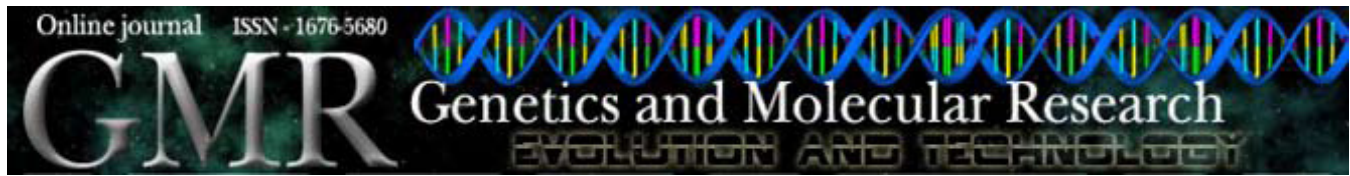

Mini-opinion

\title{
From unicellularity to multicellularity - molecular speculations about early animal evolution
}

\author{
H.F. Hoenigsberg, M.H. Tíjaro and C. Sanabria \\ Instituto de Genética Evolutiva y Biología Molecular and \\ Instituto de Genética Ecológica y Biodiversidad del Trópico Americano, \\ Bogotá D.C., Colombia \\ Corresponding autor: H.F. Hoenigsberg \\ E-mail: hoenigsberg@cable.net.com
}

Genet. Mol. Res. 7 (1): 50-59 (2008)

Received August 9, 2007

Accepted December 5, 2007

Published January 22, 2008

\begin{abstract}
A morphological, physiological, developmental, and genetic organization of great complexity ineluctably unfolded from relatively simple phenomena invested with enormous potential. Sometime long ago in the Protererozoic times, parasitic invasions caused lower evolutionary levels to integrate into higher-level selection. Therefore, we have a multi-level selection problem that ultimately revolves around the question of how natural selection among lower-level units acts to create higher-level units of selection, in which Darwinian competition among replicators ceases to be the foremost force. The first level relinquishes its independence for the benefit of a higher-level cooperative force that is now the criterion of fitness for the new transition in the evolutionary process.
\end{abstract}

Key words: Parasitic invasions; Higher-level selection; Biological evolution 


\section{INTRODUCTION}

We explore molecular and developmental consequences of the entrance of a parasite into the most basal metazoan lineage, Porifera (Kruse et al., 1998; Degnan et al., 2005) and its Choanoflagellate ancestor (King and Carroll, 2001). The enormous impact on cellular survival and on the evolution of complexity has been discussed by others (Pomiankowski, 1999). Here, we confront two biological aspects of paramount importance for the evolution of complexity to emerge: 1) The evolution of the harmonization of genetic-switch feedback (the turning on and off of both the parasite and the host's genes) as a fundamental biological process whereby genes and regulatory proteins were able to create conditions of survival in accordance with the parasite and the host DNA synthesis. 2) The creation of contingencies in prebilaterian protein kinases that gave choanoflagellates the biochemical plasticity needed to change into a new animal - the Metazoa. These contingencies manifested themselves as multiple signals resulting in new adaptations.

The entrance of the parasitic genome, probably in Proterozoic times, constituted a moment of special opportunity. We posit that invasive transportable elements (TEs), as they are frequently called, modified the choanoflagellate into a new individual. Starting from a small unexpected change inside the host's cell with the ability to respond to contingencies (Gerhart and Kirchner, 1997) in transcriptional regulation (Wray, 2003), our suspicion is that natural selection "rushed" to the chance to produce a new adaptation and profound new developmental expressions (Wray et al., 2003). The animal in question, that gradually began multicellularity as an adaptation for survival, is a choanoflagellate reputed to have a genetic toolkit appropriate for this mechanism of demise-and-challenge-for-survival (King and Carroll, 2001; King et al., 2003).

In this short, speculative paper, we explore the "ping-pong game" that the evolutionary process needed, in this case, to engulf parasitic invasions that eventually produced cooperation. In time the give-and-take of genes switching between the molecular parasite and those of the host had to gradually respond to a selection process, while allowing for a certain reduction of fitness. Even between drastic genes of the genetic load, different alleles that guide to the same adaptive response (similar to the ping-pong game we just referred to) have been repeatedly found, through the analysis of population genetics of wild strains of Drosophila melanogaster, to have adaptive features (survival) resulting from a switching between those genes that permit semi-lethality and sub-vitality without causing mortality to those that caused near-normal viability (Hoenigsberg and Navas, 1965; Hoenigsberg et al., 1968, 1969a,b, 1973).

A certain amount of genomic conflict is a widely recognized phenomenon even in extant species and clades. TEs are generally considered to be selfish genetic elements because transposition is frequently harmful to the host (Charlesworth et al., 1994). By being selfish, they promote their own survival and multiplication even to the detriment of the host's fitness (Pomiankowski, 1999). The first entrance probably occurred at low frequencies (Montgomery and Langley, 1983; Charlesworth et al., 1994). According to our theory, insertions often produce spontaneous mutations or deleterious consequences. In Drosophila and other insects, more than half of all spontaneous mutations are considered to be due to insertions (Yoder et al., 1997).

\section{ACTIVATED MAP KINASE BY ANY OTHER NAME CAN SMELL AS SWEET}

Contingency (the interaction of intra- and intercellular reactions to external conditions; Gerhart and Kirchner, 1997) during parasitic entrance in the cytoplasm can act as a transmission

Genetics and Molecular Research 7 (1): 50-59 (2008) www.funpecrp.com.br 
system form by numerous phosphorylation cascades (Hill et al., 1993). In these cascades, several kinases (serine/threonine) participate. One family (with at least five members) appears to have a singularly important role, the mitogen-activated proteins, also called the extracellular-signal-regulated kinases, with serine and threonine that interact among them in biochemical cooperation through signal pathways which regulate protein kinase (Alberts et al., 1994). Indeed, they can be considered to be that part of the somatic environment that acts on the genetic (transcription factor) environment to modify the coefficient of selection in the direction of survival (Williams, 1996). As time passed, and other parasitic entrances occurred, selected alleles participating in mitogen-activated proteins gradually diminished the original conflict between TEs and the local gene-switching. This cooperation created a better fitness that resulted in an improvement of survival.

\section{TRANSPORTABLE ELEMENTS HAD SEVERAL ENTRANCES INTO UNICELLULAR CHOANOFLAGELLATES THAT PREPARED THE WAY FOR THE REVOLUTIONARY FINAL INFECTION THAT INITIATED MULTICELLULARITY}

We posit that multiple parasitic entrances in the Proterozoic in time evolved properties to reduce mortality in transposition. It is likely that the infection of choanoflagellate organisms (as set forth in this hypothesis) had already produced species of TEs liable to reduce conflict at the moment of their special entrance. For example, TEs generally do not transpose into somatic cells today because this would irreversibly decrease the host's fitness. Nor would it enhance transmission either. According to Cech (1990), some mobile elements are able to self-splice from primary RNA transcripts (I introns). Other authors suggest that mobile elements preferentially insert themselves into regions that do not disrupt gene activity. For example, there is abundant evidence of nonrandom genomic distribution of yeast Ty 1, in which most insertions are in the promoter rather than in the coding regions (Eibel and Philippsen, 1984; Natsoulis et al., 1989). These patterns of infection bias could be interpreted as an evolutionary result that caused little or no reduction in the host's fitness. In cases like yeast Ty 3 insertions upstream to tRNA genes (Kinsey and Sandmeyer, 1991), there is room to speculate that, to some extent, the gradual improvement of sub-vitality, which in fact occurred, was due to the fact that selection acted in favor of molecular parasites that localized themselves where they would produce semi-lethality but not mortality. Moreover, there is also a negative selection in ectopic recombination with homologous units at different chromosomal sites (Langley et al., 1988).

Thus, in their parasexual connubium both genomes (the parasite's and the choanoflagellate's host) had to synchronize their optimum alleles in a new adaptive peak for selection to achieve cooperation. These cooperative interactions led to cooperative networks of genes termed hypercycles (Eigen and Schuster, 1979). They did this by trading the lowerlevel fitness of earlier Darwinian evolution to a higher-level fitness (Maynard Smith and Szathmáry, 1995). The driving force of adaptation lies in the fact that each gene contributes to the replication of other genes in a reciprocal process where it shares the beneficial effects of the molecular products produced by its neighbors. Therefore, it is imperative that conflict-mediation permanently acts during the transition to new levels of individuality (Michod, 1999).

Genetics and Molecular Research 7 (1): 50-59 (2008) www.funpecrp.com.br 


\section{PROTEIN CONTINGENCIES IN CHOANOFLAGELLATES MAKE THEM METAZOAN}

For evolution to reach a higher level of fitness, the simultaneous occurrence of cooperation and multicellularity had to take over. Due to the cooperative cellular behavior among daughter cells of the mitotic cycles, the first choanoflagellate, which dealt with a special parasitic entrance, had to invent new cell types for somatic cooperation. These molecularparasites already had a genome, which had in previous infections (previously aborted after self splicing from primary RNA transcripts) found an adaptive beginning in another host that was on the road to an endoparasitic lifestyle. We believe this is a highly probable double-infective-entrance possibility, during Proterozoic times, which lasted many millions of years under those conditions. The genetic and evolutionary events during this transition are in fact unknown, but may have produced the evolution of genes required for signaling and gene regulation in metazoans (King and Carroll, 2001).

We propose that just as extant bodies are exposed to a relentless barrage of readymade invasive pathogenic viruses and bacteria (Hoenigsberg, 2003a,b), cells of communities of choanoflagellates in Proterozoic times could have been attacked many times by similar parasites.

The phylogenetic analysis of small subunits rDNA sequences that have most frequently supported a monophyletic Metazoa/choanoflagellate clade (Ragan et al., 1996) allows us to speculate about a whole group of parasitic protists. They represent the Mesomycetozoa, which clustered with choanoflagellates and Metazoa on the eukaryotic evolutionary tree (Medina et al., 2001). The previous statement is congruent with the presence of invasive protists as populations of TEs.

Admittedly we cannot directly examine the first Metazoa, but we can infer certain details of these animals that marked the evolutionary transition between them and the basal bilaterians. This can be done, through careful comparisons of phenomena that appear in living animals. We can certainly gain insights into the biochemical and genetic innovations underlying this transition by comparing the genomes of a group of Metazoa with representatives of those in closely related protist lineages, such as choanoflagellates (Degnan et al., 2005). Although phylogenetically crucial, Reniera (Demosponge), embryogenetic biochemistry has not received all its deserved attention (Medina et al., 2001). Demosponges have been overlooked for developmental studies because their adult body plan appears simple and primitive, with little in common with the more advanced Metazoa (Brusca and Brusca, 2003). Only recently have embryogenesis and gastrulation shown startling similarities and homologies with other Metazoa (Leys, 2003a,b, 2004; Leys and Degnan, 2002; Maldonado, 2004). Although adult sponges did not seem to have any obvious body axes, nor do they even have tissue-level organization, reassessment of their morphology proves that they possess rudimentary axes and cell types for tissue organization (Bavestrello et al., 1998; Borchiellini et al., 2001; BouryEsnault et al., 2003). At the molecular genetics level, transcription factors express themselves during the embryogenesis of Reniera, most of which belong to metazoan-specific families that include members of POU, LIMHD, Pax, Bar, Prox 2, Fox, Sox, etc. (Degnan et al., 2005).

We develop this issue by working from the inside (of the cell) to the outside. Biologists can better address the invasion problem by unraveling the way in which contingency got into transcriptional control. This makes it possible to analyze how the ability to change functions in response to other ecological features enabled proteins like kinases and carmodiles to create plasticity in their responses to urgent necessities.

As far as we are concerned, contingency is a concept dependent on another factor. We

Genetics and Molecular Research 7 (1): 50-59 (2008) www.funpecrp.com.br 
believe that the essence of phenotypic plasticity and the genetic assimilation of transcription factors at the onset of prebilaterians, when TEs entered into the cell, enabled the genetic apparatus to reach a new and higher level of selection in evolutionary transition. The unicellular protist was propelled into an incipient multicellular condition. This extraordinary phenomenon conforms to the general theory of evolution through natural selection, namely: the combined effects of phenotypic variation (including protein domains and the innovative capacity deriving from their capability for contingency), differential reproductive success (including the asexual one) and heritability.

A special characteristic of most processes in the metazoan cell is that they are more contingent than those in single-celled eukaryotes (Gerhart and Kirchner, 1997). However, choanoflagellates are the exception; it has been found that the expressed sequences for signaling proteins in Monosiga brevicollis have a receptor tyrosine kinase gene, the Mbrtk1 (King and Carroll, 2001). The RTK family of signaling molecules regulates cellular and developmental pathways throughout the animal kingdom, including sponges and cnidarians (Hunter et al., 1992). Although the pattern of the evolution of Metazoa from a special choanoflagellate-like ancestor, or from choanoflagellates from a basal metazoan (Rieger and Weyrer, 1998), could help us to understand the significance of any shared genes, the diversity of signaling and the presence of accompanying molecules is certainly thought provoking. This is so because it indicates the probable use of different protein dominions in the basal animals, cnidarians and sponges. Some of these protein families may therefore have arisen even before the origin and diversification of the Metazoa (Exposito and Garrone, 1990; Brower et al., 1997; Suga et al., 1999, and others).

Contingency in response to special conditions of nutritional signals, numerous growth factors and hormonal signals from distant cells (Murray and Hunt, 1993) are common. As in other Metazoa, cells conserved core reactions of transcription, RNA splicing, polyadenylation, translation, inhibition, protein activation, degradation, and even the activation of operators in the DNA close to promoters that have been silenced. These reactions are all contingent on a variety of conditions. In fact, in the recent classic by Ptashne (2004), we read that "the CII protein works like $\lambda$ repressor in its role as a gene activator because it encourages RNA polymerase to bind and begin transcription at two promoters that would otherwise remain silent: $\mathrm{P}_{\mathrm{RE}}$ and $\mathrm{P}_{\mathrm{I}}$ ".

Moreover, the lysis-lysogeny decision of the above mentioned phage $\lambda$ can be taken as an example of how the many-phased dominions of protein can influence the choice of developmental pathways. The first steps of gene regulation that occur upon infection are identical, independent of the decision (lysis or lysogeny). However, in a certain critical cytoplasmic condition, the state of the host is sensed by a phage regulatory protein and subsequent steps then precisely follow one of the two pathways (Ptashne, 2004).

\section{CELLULAR SIGNALING REGULATION AND THE NEW LEVEL OF CELLULAR COOPERATION}

The intercellular response to the TE invasion that occurred before the emergence of the clade, which gave rise to the crown taxa, required a number of innovations. One of them, in line with selection, was the acquisition of multicellularity through reproduction and the emergence of new cell types that had an extracellular matrix for cell support, movement and the localization of differentiation.

These cells probably had the capacity to communicate by using an innovative signaling pathway component, such as receptor tyrosine kinases. The clone of these cells

Genetics and Molecular Research 7 (1): 50-59 (2008) www.funpecrp.com.br 
very likely inhabited a self-generated extracellular matrix using cadherins and C-type lectins encoded in choanoflagellate protist genomes (King et al., 2003). There was an evident selective advantage for clones in which cell-differentiating events took place that responded contingently to these new signaling mechanisms.

For example, TGF- $\beta$ and Wnt pathways (Suga et al., 1999; Adell et al., 2003, among others) are systems that may originally have had the capacity to respond to endogenous and exogenous signals. Thus, our point is that the creation of contingencies in basic, conserved choanoflagellate processes that had just initiated multicellularity by engaging in cooperative behavior with the first few products of mitosis was meant "to squeeze out" all they could from cooperation in order to optimize efficient energy consumption at the higher level of selection they embraced. At this new stage of transition, cooperation will prevail because the cell population structure leads to non-random associations that, in turn, heighten genetic relatedness between interacting products of mitotic cycles (Maynard Smith and Szathmáry, 1995). The evolution of the Pre-bilaterian multicellularity which starts with choanoflagellates reminds us that spatially structured populations with mitotic clones exploit kin selection and underlying genetic relatedness. Thus, kin selection played an important role in evolutionary transitions, which in this case represent the new unit of selection, namely the individuals (Michod, 1997, 1999). These are then grouped into cells that are localized in space and time.

Genetic relatedness is a deterrent to conflict (Hamilton, 1964; Williams, 1966, 1971). Moreover, lowering the somatic mutation rate and limiting the total number of cells per aggregate restrict genetic variation within aggregates (Michod, 1997).

Through conventional natural selection and the adaptive response for a higher level of selection during a transition phase from the cellular to the multicellular, evolution basically conserved protein contingencies among choanoflagellate mitotic products. Moreover, it gave them a better than even chance of finding the new instrument of plasticity and functional contingency that would make them more efficient. Simple logic leads us to agree with Michod's classic statement that cooperation helps protect the cooperative unit from cheaters and interlopers (Michod, 1999, p. 42). This acquires profound significance because it explains why a choanoflagellate cell in transition may experiment with multicellularity.

Our proposal is in perfect agreement with the conventional Darwinian explanation of a new transition during evolution.

\section{METAZOAN PROTEINS AS CONFLICT-MODIFIERS THROUGH CONTINGENCIES OF G-PROTEINS AND KINASES}

The positioning of protists such as choanoflagellates as organized colonies in the phylogeny of basal Prebilaterians (Leadbeater, 1983) is a reason for suggesting them as possible candidates for the earliest experiments in multicellularism. Furthermore, some choanoflagellates have been found to possess an amazing biochemical and genetic toolkit, along with dominions in protein kinases and phosphatases appropriate for cellular communication (King and Carroll, 2001). In fact, multiple members of cell-signaling and adhesion-gene families have recently been found in the most basal Metazoa, sponges and cnidarians, indicating that these protein families probably persisted before the origin of extant species of Metazoa (Exposito and Garrone, 1990; Brower et al., 1997; Suga et al., 1999).

Genetics and Molecular Research 7 (1): 50-59 (2008) www.funpecrp.com.br 
Contingencies are so important for intra- and intercellular communication that the evolution of metazoan phylogeny has almost never managed to fix each contingent response. In other words, in addition to specific or ad hoc mechanisms to produce contingent reactions, there are also specialized contingency generators, such as the numerous protein kinases that have been selected for their capacity to impose contingency (Peter and Herskowitz, 1994; Lehming et al., 1994; Thanos and Maniatis, 1995; Gerhart and Kirchner, 1997). This phenomenon has yielded evidence for a pervasive use of contingency in Metazoa and very likely in Prebilaterians that originated them, and should be biology's next exploration. The enormous amount of kinases (about 2000) and phosphatases (about 1000) encoded in the human genome is an indication of the widespread use of protein kinase to catalyze the transfer of a phosphate group from ATP to selected amino acid side-chains on proteins; in fact they comprise large, diversified protein families (Hunter, 1995). Their widespread use has been found in prokaryotes as well, targeting serine (Fischer et al., 1996). To be metazoan is to respond to a variety of environmental insults without jeopardizing survival. They are always there as a statistical result of a polygenic inheritance in which plasticity, acting with modularity, allows for variety. How could this have happened in the earliest days of the cell-cell communication system?

Polymorphic plasticity can be attributed to a wide variety of specifically evolved adaptations. Indeed, as the environment grew more complex, the cell's response to particular conditions necessary for survival and cell division became more precisely specified (Williams, 1996). Choanoflagellates are no exception and, during the course of evolution, participation in the genetic variation and selective processes of kinases and G-proteins became paradigms of unicellular and multicellular adaptations. Adopting variable dominions that facilitated molecular interactions contingent on new internal or external conditions could have been fatal to evolution if mutation, as a random change, could operate anywhere and everywhere. Following Fisher (1958), we know that the larger $n$ is, the smaller the probability of improvement, in other words, the molecule (or the characteristic) affected by the mutation is more complex. Fisher has, therefore, argued that mutations with small effects have disproportionately contributed to the raw material of adaptive evolution. The modular organization of genes and the characteristics they affect are essential to making adaptive evolution possible. As Lewontin (1978) suggested in his brilliant proposal, modularity allows one feature to be changed without changing any others. Wagner (1996) suggested that directional selection in one feature can accompany a stabilizing selection in the rest of the phenotype. This could mean that selective pressures acting on different life-history stages (Stearns, 2000) are due to modularity. Moreover, Gerhart and Kirchner's (1997) evolution of "evolvability" and Hoenigsberg's similar theory (2003a,b) are just as possible, thanks to Lewontin's modularity.

Kinases and G-proteins can bind conserved core reactions to other contingent and housekeeping reactions. The evolution of contingency and variable contingent reactions give intra- and intercell signaling network capabilities for evolving complex communications. In view of the fact that some choanoflagellate species are capable of forming organized colonies (Leadbeater, 1983), it is possible that certain gene products came from earlier parasitic invasions (around $600 \mathrm{Ma}$ ), when oxygen levels in the environment determined the rise of complex multicellular life (Hedges et al., 2004) in the Proterozoic. Gene products required for metazoan multicellularity could have emerged in the common ancestor of the choanoflagellates and metazoans. Indeed, conserved proteins from a unicellular choanoflagellate, Monosiga brevicollis, provide important support for a close relationship between choanoflagellates and metazoans (King and Carroll, 2001).

Genetics and Molecular Research 7 (1): 50-59 (2008) www.funpecrp.com.br 


\section{ACKNOWLEDGMENTS}

Although interesting in some ways, comments from one anonymous referee were not followed but are gratefully acknowledged. We thank Juan Carlos Rojas, Maria Estela Arrieta, Hugo Dávila, Fernando Ariza, José Dilmer Moreno, Emerson McCoy, Ana Maria Pressiga, and Camila Oliveros for helpful discussions and assistance with phylogenetic analysis now in process. Our student staff in Biomedical engineering at the Institute made important and decisive comments that improved our view of the homologies of the prebilaterians and the main Metazoa. Critical reading of the manuscript and corrections by H. Rubinstein and Jimmy Weiskopf were gladly followed. We gratefully acknowledge suggestions by the staff of the Institute about new methods of biochemical research in seminars that enriched topics related to parasitic invasions. Finally, expert technical assistance by Felipe Acosta, Leonel Reyes, Luis Alexander Jimenez, and Jasmine Mayorga are gratefully acknowledged.

\section{REFERENCES}

Adell T, Nefkens I and Muller WE (2003). Polarity factor 'Frizzled' in the demosponge Suberites domuncula: identification, expression and localization of the receptor in the epithelium/pinacoderm. FEBS Lett. 554: 363-368.

Alberts BM, Bray D, Lewis J, Raff M, et al. (1994). Molecular biology of the cell. 3rd edn. Garland Publishing Inc., New York.

Bavestrello G, Benatti U, Calcinai B, Cattaneo-Vitelli R, et al. (1998). Body polarity and mineral selectivity in the demosponge Chondrosia reniformis. Biol. Bull. 195: 120-125.

Borchiellini C, Manuel M, Alivon E, Boury-Esnault N, et al. (2001). Sponge paraphyly and the origin of Metazoa. J. Evol. Biol. 14: 171-179.

Boury-Esnault N, Ereskovsky A, Bezac C and Tokina D (2003). Larval development in the Homoscleromorpha (Porifera, Demospongiae). Invert. Biol. 122: 187-202.

Brower DL, Brower SM, Hayward DC and Ball EE (1997). Molecular evolution of integrins: genes encoding integrin beta subunits from a coral and a sponge. Proc. Natl. Acad. Sci. USA 94: 9182-9187.

Brusca RC and Brusca GJ (2003). The invertebrates. Sinauer Associates. Sunderland.

Cech TR (1990). Self-splicing of group I introns. Annu. Rev. Biochem. 59: 543-568.

Charlesworth B, Sniegowski P and Stephan W (1994). The evolutionary dynamics of repetitive DNA in eukaryotes. $\mathrm{Na}$ ture 371: 215-220.

Degnan BM, Leys SP and Larroux C (2005). Sponge development and antiquity of animal pattern formation. Integr. Comp. Biol. 45: 335-341.

Eibel H and Philippsen P (1984). Preferential integration of yeast transposable element Ty into a promoter region. Nature 307: 386-388.

Eigen M and Schuster P (1979). The hypercycle, principle of natural self-organization. Springer-Verlag, Berlin.

Exposito JY and Garrone R (1990). Characterization of a fibrillar collagen gene in sponges reveals the early evolutionary appearance of two collagen gene families. Proc. Natl. Acad. Sci. USA 87: 6669-6673.

Fischer C, Geourjon C, Bourson C and Deutscher J (1996). Cloning and characterization of the Bacillus subtilis prkA gene encoding a novel serine protein kinase. Gene 168: 55-60.

Fisher RA (1958). The genetical theory of natural selection. Dover Press, New York.

Gerhart J and Kirchner M (1997). Cells, embryos and evolution. Blackwell Science, Malden.

Hamilton WD (1964). The genetical evolution of social behaviour. I. J. Theor. Biol. 7: 1-16.

Hedges BS, Blair JE, Venturini Maria L and Shoe JL (2004). A complex molecular timescale of eukaryote evolution and the rise of complex multicellular life. BMC Evol. Biol. 4: 2.

Hill CS, Marais R, John S, Wynne J, et al. (1993). Functional analysis of a growth factor-responsive transcription factor complex. Cell 73: 395-406.

Hoenigsberg HF (2003a). Cell biology, molecular embryology, Darwinian and Lamarckian evolvability. Genet. Mol. Res 2: 7-28.

Hoenigsberg HF (2003b). Non Darwinian and Darwinian prokaryotic and eukaryotic evolution - an enigma in cell biology conservation. Genet. Mol. Res. 2: 279-287.

Hoenigsberg HF and Navas YG (1965). Population genetics in the American tropics. I. Concealed recessives in different

Genetics and Molecular Research 7 (1): 50-59 (2008) www.funpecrp.com.br 
bioclimatic regions. Evolution 19: 506-513.

Hoenigsberg HF, Castro LE and Granobles LA (1968). Population genetics in the American tropics. III. The genetic role of heterozygous individuals in various Colombian populations of D. melanogaster. Evolution 22: 66-75.

Hoenigsberg HF, Granobles LA and Castro LE (1969a). Population genetics in the American tropics. IV. Temporal changes effected in natural populations of Drosophila melanogaster from Colombia. Genetica 40: 201-215.

Hoenigsberg HF, Castro LE and Granobles LA (1969b). Population genetics in the American tropics. V. The sterility content in the second chromosomes of Drosophila melanogaster from Fusagasuga, Colombia. Genetica 40: 543-554.

Hoenigsberg HF, Castro LE, Granobles LA and Saez A (1973). Population genetics in the American tropics. IX. Rhymic genetics changes that prove the adaptive nature of the detrimental load in Drosophila melanogaster from Caracolisito, Colombia. In: Genes, enzymes and populations (Adrian M. Srb, ed.). Plenum Publishing Corporation, New York.

Hunter T (1995). Protein kinases and phosphatases: the yin and yang of protein phosphorylation and signaling. Cell 80 : 225-236.

Hunter T, Lindberg RA, Middlemas DS, Tracy S, et al. (1992). Receptor protein tyrosine kinases and phosphatases. Cold Spring Harbor Symp. Quant. Biol. 57: 25-41.

King N and Carroll SB (2001). A receptor tyrosine kinase from choanoflagellates: molecular insights into early animal evolution. Proc. Natl. Acad. Sci. USA 98: 15032-15037.

King N, Hittinger CT and Carroll SB (2003). Evolution of key cell signaling and adhesion protein families predates animal origins. Science 301: 361-363.

Kinsey PT and Sandmeyer SB (1991). Adjacent pol II and pol III promoters: transcription of the yeast retrotransposon Ty3 and a target tRNA gene. Nucleic Acids Res. 19: 1317-1324.

Kruse M, Leys SP, Muller IM and Muller WE (1998). Phylogenetic position of the Hexactinellida within the phylum Porifera based on the amino acid sequence of the protein kinase C from Rhabdocalyptus dawsoni. J. Mol. Evol. 46: 721-728.

Langley CH, Montgomery E, Hudson R, Kaplan N, et al. (1988). On the role of unequal exchange in the containment of transposable element copy number. Genet. Res. 52: 223-235.

Leadbeater BC (1983). Life-history and ultrastructure of a new marine species of Proterospongia (Choanoflagellida). $J$. Mar. Biol. Assoc. 63: 135-160.

Lehming N, Thanos D, Brickman JM, Ma Jun, et al. (1994). An HMG-like protein that can switch a transcriptional activator to a repressor. Nature 371: 175-179.

Lewontin RC (1978). Adaptation. Sci. Am. 239: 212-8, 220, 222.

Leys SP (2003a). Comparative study of spiculogenesis in demosponge and hexactinellid larvae. Microsc. Res. Tech. 62: 300-311.

Leys SP (2003b). The significance of syncytial tissues for the position of the Hexactinellida in the Metazoa. Integr. Comp. Biol. 43: 19-27.

Leys SP (2004). Gastrulation in sponges. In: Gastrulation: from cells to embryos (Stern C, ed.). Cold Spring Harbor Press, Cold Spring Harbor, 23-31.

Leys SP and Degnan BM (2002). Embryogenesis and metamorphosis in a haplosclerid demosponge: Gastrulation and transdifferentiation of larval ciliated cells to choanocytes. Invert. Biol. 121: 171-189.

Maldonado M (2004). Choanoflagellates, choanocytes and animal multicellularity. Invert. Biol. 123: 1-22.

Maynard Smith J and Szathmary E (1995). The mayor transitions in evolution. W.H. Freeman, San Francisco.

Medina M, Collins AG, Silberman JD and Sogin ML (2001). Evaluating hypotheses of basal animal phylogeny using complete sequences of large and small subunit rRNA. Proc. Natl. Acad. Sci. USA 98: 9707-9712.

Michod RE (1997). Cooperation and conflict in the evolution of individuality. 1. Multilevel selection of the organism. Am. Nat. 149: 607-645.

Michod RE (1999). Darwinian dynamics, evolutionary transitions in fitness and individuality. Princeton University Press, Princeton.

Montgomery EA and Langley CH (1983). Transposable elements in Mendelian populations. II. Distribution of three Copia-like elements in a natural population of Drosophila melanogaster. Genetics 104: 473-483.

Murray A and Hunt T (1993). The cell cycle: an introduction. Oxford University Press, New York.

Natsoulis G, Thomas W, Roghmann MC, Winston F, et al. (1989). Ty1 transposition in Saccharomyces cerevisiae is nonrandom. Genetics 123: 269-279.

Peter M and Herskowitz I (1994). Joining the complex: cyclin-dependent kinase inhibitory proteins and the cell cycle. Cell 79: 181-184.

Pomiankowski A (1999). Intragenomic conflict. In: Levels of selection in evolution (Keller L, ed.). Princeton University Press, Princeton, 413.

Ptashne M (2004). A genetic switch. Cold Spring Harbor Laboratory Press, New York.

Ragan MA, Goggin CL, Cawthorn RJ, Cerenius L, et al. (1996). A novel clade of protistan parasites near the animal-fungal

Genetics and Molecular Research 7 (1): 50-59 (2008) www.funpecrp.com.br 
divergence. Proc. Natl. Acad. Sci. USA 93: 11907-11912.

Rieger R and Weyrer S (1998). In molecular evolution: towards the origin of Metazoa. Vol. 21. Springer Verlag, Belin, 21-41.

Stearns SC (2000). Life history evolution: successes, limitations, and prospects. Naturwissenschaften 87: 476-486.

Suga H, Koyanagi M, Hoshiyama D, Ono K, et al. (1999). Extensive gene duplication in the early evolution of animals before the parazoan-eumetazoan split demonstrated by $\mathrm{G}$ proteins and protein tyrosine kinases from sponge and hydra. J. Mol. Evol. 48: 646-653.

Thanos D and Maniatis T (1995). NF-kappa B: a lesson in family values. Cell 80: 529-532.

Wagner A (1996). Genetic redundancy caused by gene duplications and its evolution in networks of transcriptional regulators. Biol. Cybern. 74: 557-567.

Williams GC (1966). Adaptation and natural selection. 1st edn. Princeton University Press, Princeton.

Williams GC (Editor) (1971). Group selection. Aldine-Atherton, Chicago.

Williams GC (1996). Adaptation and natural selection. 2nd edn. Princeton University Press, Princeton.

Wray GA (2003). Transcriptional regulation and the evolution of development. Int. J. Dev. Biol. 47: 675-684.

Wray GA, Hahn MW, Abouheif E, Balhoff JP, et al. (2003). The evolution of transcriptional regulation in eukaryotes. Mol. Biol. Evol. 20: 1377-1419.

Yoder JA, Walsh CP and Bestor TH (1997). Cytosine methylation and the ecology of intragenomic parasites. Trends Genet. 13: 335-340.

Genetics and Molecular Research 7 (1): 50-59 (2008) www.funpecrp.com.br 